\title{
Bonding Characteristics of Macrosynthetic Fiber in Latex-Modified Fiber-Reinforced Cement Composites as a Function of Carbon Nanotube Content
}

\author{
Ji-Hong Jean, ${ }^{1}$ Chan Yu, ${ }^{2}$ and Chan-Gi Park ${ }^{3}$ \\ ${ }^{1}$ Department of Environmental Engineering, Andong National University, Andong 74760, Republic of Korea \\ ${ }^{2}$ Department of Agricultural Engineering, Institute of Agricultural and Life Science, Gyeongsang National University, \\ Jinju 52828, Republic of Korea \\ ${ }^{3}$ Department of Rural Construction Engineering, Kongju National University, Yesan 32439, Republic of Korea
}

Correspondence should be addressed to Chan-Gi Park; cgpark@kongju.ac.kr

Received 25 September 2015; Accepted 16 February 2016

Academic Editor: Sohel Rana

Copyright ( 2016 Ji-Hong Jean et al. This is an open access article distributed under the Creative Commons Attribution License, which permits unrestricted use, distribution, and reproduction in any medium, provided the original work is properly cited.

\begin{abstract}
The effect of carbon nanotube content $(0,0.5,1.0,1.5$, and $2.0 \%$ of the cement weight) on the bonding properties of macrosynthetic fiber in latex-modified hybrid fiber cement-based composites (LMHFRCCs) was evaluated. The slump value, compressive strength, and bonding strength were measured for each LMHFRCC. As the carbon nanotube content increased to $1.5 \%$, the bonding properties of the macrosynthetic fiber improved. However, the bonding performance deteriorated at a carbon nanotube content of $2.0 \%$. A decrease in the fluidity of the mix negatively affected the dispersion of the nanotubes in the LMHFRCCs. The addition of carbon nanotubes also affected the relative bonding strength independently of the improvement in compressive strength. Microscopic analysis of the macrosynthetic fiber surfaces was used to understand changes in the bonding behavior.
\end{abstract}

\section{Introduction}

Carbon nanotubes are an attractive reinforcing material for cement composites $[1,2]$. Mechanical testing has shown that these nanotubes have an elastic modulus greater than $1 \mathrm{TPa}$ and a tensile strength greater than 20-100 GPa $[1,3]$. They have been used widely in electronics, biotechnology, chemistry, and composites $[4,5]$. The reinforcing effect of carbon nanotubes in concrete is expected to be very large [68]. Carbon nanotubes can be differentiated from traditional concrete reinforcing fibers that are used as stiffeners in high-strength/high-performance concretes [4, 8-10]. First, the much greater strength and stiffness of carbon nanotubes improve the overall mechanical performance of the concrete. Second, their high aspect ratio suppresses the generation and growth of macro-, micro-, and nanosized cracks. Third, they can be more easily dispersed [4, 5]. Hybrid-fiberreinforced cement-based composites (HFRCCs) are formed by combining two or more types of reinforcing fibers. Proper selection of the fiber types can improve the physical and mechanical properties of the cement-based composites [11]. When a fiber-reinforced cement-based composite is blended with fibers that are physically and mechanically different, the durability and mechanical performance improve due to better control over cracking, which is attributable to the properties of each fiber [11]. Crack control in HFRCC is dependent on the nature of the bonding of the reinforcing fiber. Reinforcing fibers suppress crack propagation in cement-based composites by fiber bridging, debonding, pullout, and fracture [12-15]. With HFRCCs, large stresses may occur because the microfibers control the formation and propagation of microcracks; hence, the flexural performance of cement-based composites improves [11]. Furthermore, the pullout behavior of macrofibers can be controlled by the fiber bonding mechanisms of microfiber in the debonded zone [11]. The emergence of carbon nanotubes has enabled the production of hybrid macro-/nanofiber-reinforced cementbased composites [8]. The effect of such hybrid fibers in 
TABLE 1: Properties of cement.

\begin{tabular}{|c|c|c|c|c|c|c|c|}
\hline \multirow{2}{*}{ Fineness $\left(\mathrm{cm}^{2} / \mathrm{g}\right)$} & \multirow{2}{*}{ Density $\left(\mathrm{g} / \mathrm{mm}^{3}\right)$} & \multirow{2}{*}{ Stability (\%) } & \multicolumn{2}{|c|}{ Setting time } & \multicolumn{3}{|c|}{ Compressive strength (MPa) } \\
\hline & & & Initial (min) & Final (min) & 3 days & 7 days & 28 days \\
\hline 3,200 & 3.15 & 0.02 & 220 & 400 & 20 & 30 & 38 \\
\hline
\end{tabular}

TABle 2: Properties of fine aggregate.

\begin{tabular}{lcc}
\hline Density $\left(\mathrm{g} / \mathrm{mm}^{3}\right)$ & Absorption $(\%)$ & Fineness modulus \\
\hline 2.62 & 0.67 & 2.99 \\
\hline
\end{tabular}

cement-based composites can be maximized by incorporating carbon nanotubes; however, the dispersion of carbon nanotubes is poor in cement-based composites $[9,15,16]$. To improve the performance of cement-based composites, the nanotubes should be well dispersed [15]. There have been several studies of methods of dispersing carbon nanotubes [15].

In this work, latex was added to improve carbon nanotube dispersion that can be negatively impacted due to a decrease in fluidity that occurs for large volume fractions of nanotubes. Improving the dispersibility of the nanotubes is expected to improve the bonding performance of cement-based composites and macrosynthetic fibers.

The SB latex polymer was a milky semitransparent liquid containing surfactant-coated organic particles $(0.5-5 \mu \mathrm{m}$ in diameter) $[10,14,17]$. The surfactant was used to stabilize the particles, delay solidification, and increase the workability at low water/cement ratios, allowing the SB latex polymer particles to form a film during hydration [10, 14, 17]. SB latex polymer incorporation can increase the dispersion of carbon nanotubes by improving the workability, as well as increase the adhesion between materials $[10,14,17]$.

This study investigated the effect of carbon nanotubes on the bonding properties of macrosynthetic fibers with latexmodified hybrid-fiber-reinforced cement-based composites (LMHFRCCs). We investigated the bonding properties of macrosynthetic fibers in hybrid macro-/nanofiber-reinforced LMHFRCCs with various carbon nanotube mass fractions.

\section{Experimental Program}

2.1. Materials. ASTM type I cement (with a density of $3.14 \mathrm{~g} \mathrm{~mm}^{-3}$ ) was used with fine aggregate (with a density of $\left.2.61 \mathrm{~g} \mathrm{~mm}^{-3}\right)$. Table 1 lists the physical properties of the cement (Sung-Sin Cement Co., Korea), and Table 2 lists the physical characteristics of the fine aggregate (Mi-Jin Aggregate Co., Korea). Table 3 lists the properties of the carbon nanotubes (Carbon Nano Materials Technology Co.). The properties of the latex (Jung-Ang Polytec, Korea) are given in Table 4. Macrosynthetic fibers were used for reinforcement (average length: $300 \mathrm{~mm}$; diameter: $1 \mathrm{~mm}$ ). Table 5 lists the properties of the fibers (Nycon Materials Co., Korea).

2.2. Mix Proportions. Table 6 lists the mix proportions of the LMHFRCCs. The bonding properties of macrosynthetic fiber

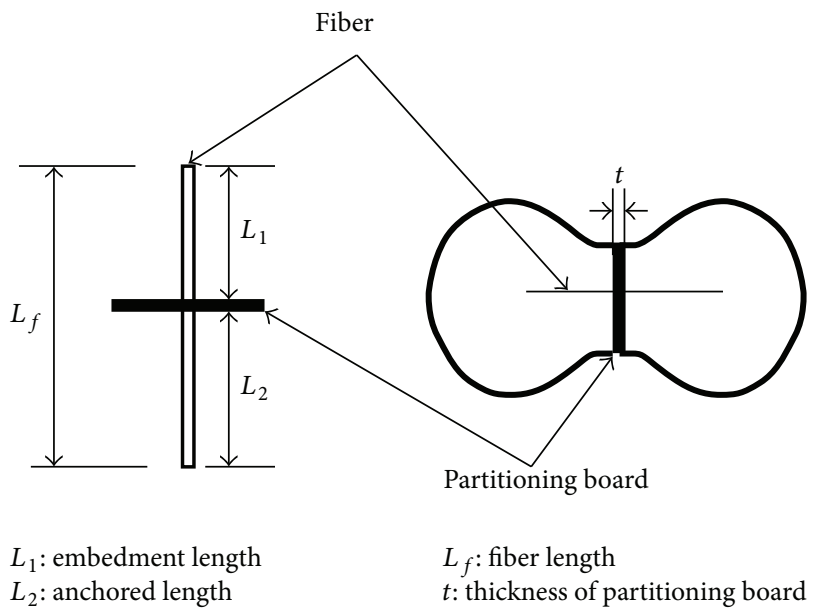

Figure 1: Arrangement of the partitioning board and fibers and setting in the mold.

for carbon nanotube contents of $0,0.5,1.0,1.5$, and $2.0 \%$ of the cement weight were evaluated. Two types of high-strength mixes were prepared, and the effect of the carbon nanotube content on the pullout characteristics of the macrosynthetic fiber was evaluated. The quantity of SB latex polymer was $10 \%$ by weight of the binder.

\section{Test Methods}

3.1. Slump and Compressive Strength. Slump tests were carried out according to the ASTM C143/C143M-15 standard [18]. Compressive strength tests were conducted according to the ASTM C109/C109M-05 standard [19].

3.2. Bonding Performance. Dog-bone-shaped specimens were prepared using a mold based on the JCI SF-8 standard (Figure 1) [20]. The specimen was divided in half and then a reinforcing fiber was anchored in the middle. The length of the fiber (embedded length + anchored length) buried in the cement-based composites was $29 \mathrm{~mm}$. The specimen used in the bonding experiment was initially cured at a temperature of $23 \pm 2^{\circ} \mathrm{C}$ and a relative humidity of $50 \%$ for $24 \mathrm{~h}$ after fabrication and was then demolded. Then, it was wet-cured under water at $23 \pm 2^{\circ} \mathrm{C}$ for 28 days. The specimen was placed in a universal testing machine and tested under displacement control at a loading rate of $0.4 \mathrm{~mm} \mathrm{~min}^{-1}$. Six specimens were fabricated and tested; the average value of the six tests was used to calculate the fiber bonding strength according to [12]

$$
\tau_{\max }=\frac{P_{\max }}{\pi D L}
$$


TABLE 3: Properties of carbon nanotube.

\begin{tabular}{lccccc}
\hline External diameter $(\mathrm{nm})$ & Length $(\mu \mathrm{m})$ & Purity $(\%)$ & Surface area $\left(\mathrm{m}^{2} / \mathrm{g}\right)$ & Amorphous carbon $(\%)$ & Electric conductivity $(\mathrm{s} / \mathrm{cm})$ \\
\hline $10-30$ & $0.5-500$ & 95 & $40-300$ & 3 & $10^{2}-10^{-4}$
\end{tabular}

TABLE 4: Properties of styrene butadiene latex.

\begin{tabular}{lccccccc}
\hline $\begin{array}{l}\text { Solids } \\
\text { content (\%) }\end{array}$ & $\begin{array}{c}\text { Styrene } \\
\text { content (\%) }\end{array}$ & $\begin{array}{c}\text { Butadiene } \\
\text { content (\%) }\end{array}$ & $\mathrm{pH}$ & $\begin{array}{c}\text { Density } \\
\left(\mathrm{g} / \mathrm{mm}^{3}\right)\end{array}$ & $\begin{array}{c}\text { Surface } \\
\text { tension } \\
(\text { dyne/cm })\end{array}$ & $\begin{array}{c}\text { Particle } \\
\text { size }(\dot{\mathrm{A}})\end{array}$ & $\begin{array}{c}\text { Viscosity } \\
(\mathrm{cps})\end{array}$ \\
\hline 46.5 & $34 \pm 1.5$ & $66 \pm 1.5$ & 11.0 & 1.02 & 30.57 & 1700 \\
\hline
\end{tabular}

TABle 5: Properties of macrosynthetic fiber.

\begin{tabular}{lccccc}
\hline Elastic modulus $(\mathrm{GPa})$ & Density $\left(\mathrm{g} / \mathrm{mm}^{3}\right)$ & Fiber length $(\mathrm{mm})$ & Fiber diameter $(\mathrm{mm})$ & Aspect ratio & Tensile strength $(\mathrm{MPa})$ \\
\hline 10 & 0.91 & 30 & 1 & 30 & 550 \\
\hline
\end{tabular}

TABLE 6: Mix proportions.

\begin{tabular}{|c|c|c|c|c|c|c|}
\hline \multirow{2}{*}{ Type of mix } & \multirow{2}{*}{$w / c(\%)$} & \multicolumn{5}{|c|}{ Unit weight $\left(\mathrm{kg} / \mathrm{m}^{3}\right)$} \\
\hline & & Cement & Water & Fine aggregate & Carbon nanotube & SB latex polymer \\
\hline \multirow{5}{*}{ Number 1} & \multirow{5}{*}{0.5} & 679 & \multirow{5}{*}{303.4} & \multirow{5}{*}{1154} & 0 & \multirow{5}{*}{67.9} \\
\hline & & 675.6 & & & 3.4 & \\
\hline & & 672.2 & & & 6.8 & \\
\hline & & 668.8 & & & 10.2 & \\
\hline & & 665.4 & & & 13.6 & \\
\hline \multirow{5}{*}{ Number 2} & \multirow{5}{*}{0.4} & 907 & \multirow{5}{*}{314.01} & \multirow{5}{*}{907} & 0 & \multirow{5}{*}{90.7} \\
\hline & & 902.4 & & & 4.6 & \\
\hline & & 897.9 & & & 9.1 & \\
\hline & & 893.4 & & & 13.6 & \\
\hline & & 888.8 & & & 18.2 & \\
\hline
\end{tabular}

where $\tau_{\max }$ is the maximum pullout strength, $P_{\max }$ is the maximum pullout load, $D$ is the fiber diameter, and $L$ is the embedded fiber length.

\section{Results and Discussion}

4.1. Slump. The slump steadily decreased with increasing carbon nanotube content (Figure 2). As the carbon nanotube content increased from 0 to $0.5,1.0,1.5$, and $2.0 \%$, the slump value for the mixes with $w / c=0.5$ changed from 300 to $300,190,100$, and $1 \mathrm{~mm}$, respectively, and that for the mixes with $w / c=0.4$ changed from 300 to 250 , 120,70 , and $1 \mathrm{~mm}$, respectively. Note that, when the slump value exceeded $300 \mathrm{~mm}$, this was represented as $300 \mathrm{~mm}$. No slump was observed for a carbon nanotube content of $2.0 \%$; therefore, mixing and compaction of these LMHFRCCs was not feasible.

4.2. Compressive Strength. Figure 3 shows the results of compressive strength testing. For number $1 \mathrm{mix}$ with a water/cement ratio $(w / c)=0.5$, as the amount of nanotubes increased from 0 to $0.5,1.0,1.5$, and $2.0 \%$, the compressive strength changed from 48.16 to 50.21, 52.21, 54.00, and $49.12 \mathrm{MPa}$, respectively. For number 2 mix with $w / c=0.4$,

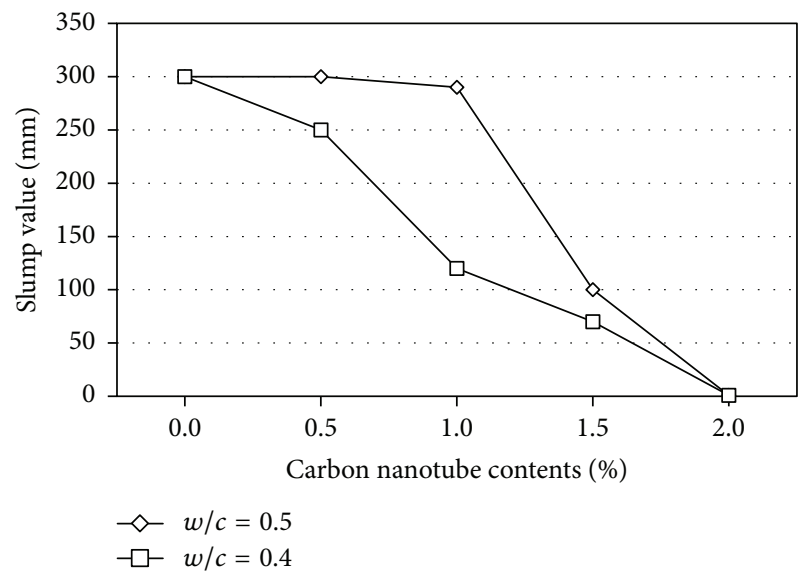

FIGURE 2: Slump test results of LMHFRCCs.

as the carbon nanotube content increased from 0 to 0.5 , $1.0,1.5$, and $2.0 \%$, the compressive strength changed from 52.64 to $59.04,63.53,66.05$, and $57.57 \mathrm{MPa}$, respectively. The maximum compressive strength was thus achieved with a carbon nanotube content of $1.5 \%$ for both the $w / c=0.5$ and 0.4 mixes. However, no significant change in the compressive 


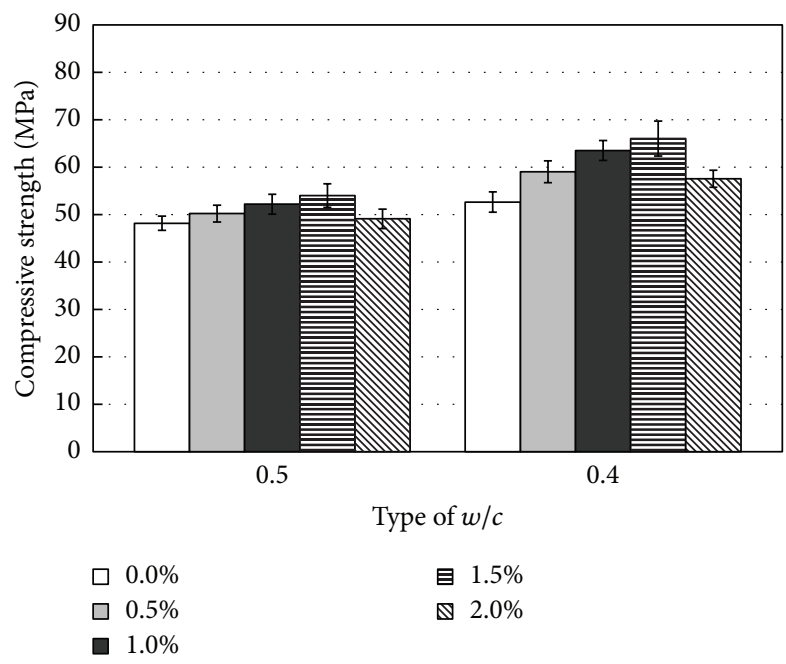

FIGURE 3: Compressive strength test results of LMHFRCCs.

strength was observed. We may expect a greater effect on the flexural and tensile strengths than on the compressive strength, because the carbon nanotubes increase strength by suppressing crack propagation and filling the nano- and micropores in the LMHFRCCs.

4.3. Pullout Behavior. Figure 4 shows the effect of the carbon nanotubes on the fiber pullout behavior. The pullout loads varied, but all showed elastic behavior before crack initiation. The interfacial strength between the reinforcing fiber- and cement-based composites affected the pullout load over the entire crack generation zone. The carbon nanotubes increased the crack initiation load because they effectively filled nanosized pores at the interface and increased the interfacial bonding performance by suppressing the generation and growth of nanosized cracks. Well-dispersed carbon nanotubes were superior to nondispersed nanotubes in terms of suppressing pullout of the macrosynthetic fibers, and the bonding performance of macrosynthetic fiber improved. At the highest carbon nanotube content of $2.0 \%$, however, the pullout load decreased due to a reduction in the fluidity of the cement-based composites and poor dispersion of the nanotubes. The crack initiation load decreased for the mixes with $w / c=0.5$ and $w / c=0.4$ at this carbon nanotube content. The separation zone after crack generation was also affected by the carbon nanotube content. For both the $w / c=$ 0.4 and 0.5 mixes in the absence of nanotubes, although the pullout loads differed, the load decreased markedly after crack initiation and continued to decrease during the pullout, even in the separation zone. The mixes containing carbon nanotubes behaved differently. In the separation zone, which was evident after the pullout load had decreased following crack initiation, the load increased with increasing displacement up to a nanotube content of $1.5 \%$ but then decreased slightly at $2.0 \%$. For a nanotube content of $0.5 \%$, the pullout load decreased slightly with increasing displacement. The displacement at which the pullout load increased was greater for the $1.0 \%$ nanotube content than the $0.5 \%$ level,

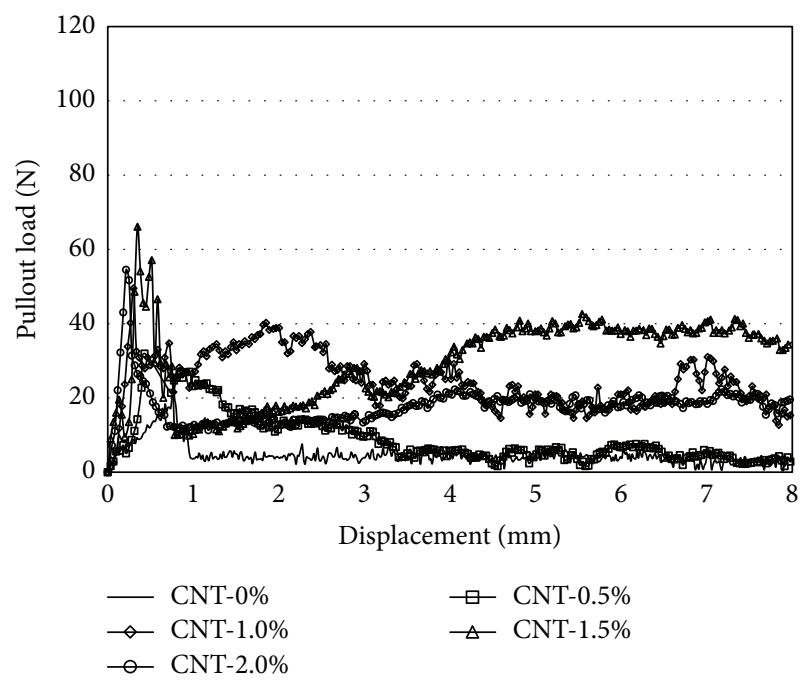

(a) $w / c=0.5$

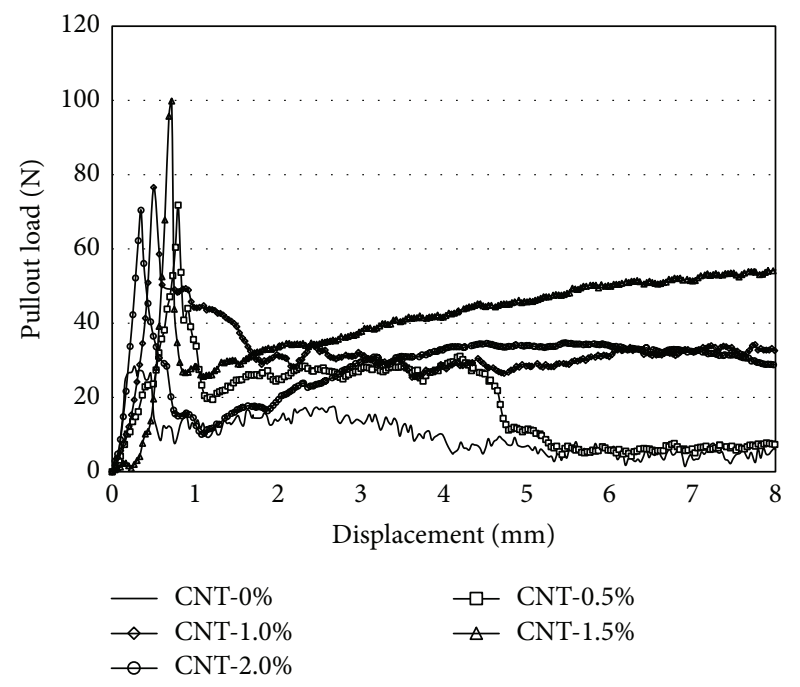

(b) $w / c=0.4$

FIGURE 4: Pullout behavior of macrosynthetic fiber in LMHFRCCs.

and the pullout load also increased. At the $1.5 \%$ level, both the zone in which the pullout load increased while the displacement increased and the magnitude of the pullout load changed remarkably. The pullout load was higher at the $2.0 \%$ level, but it began to decrease in the displacement zone. These results are consistent with the carbon nanotubes suppressing the growth of nanoscale cracks generated at the interface between the macrosynthetic fibers and the cementbased composites through fiber bridging during pullout and then suppressing the pullout of the macrosynthetic fibers during crack growth. Therefore, the pullout behavior of macrosynthetic fiber improved. The pullout performance of the reinforcing fiber also improved. At the highest carbon nanotube content of $2.0 \%$, the tramping and dispersion of the carbon nanotubes were detrimentally affected. The different behaviors of the mixes with $w / c=0.4$ and 0.5 occurred due to the compressive strength of the cement-based composites. If the strength is high, then so is the interfacial bonding 


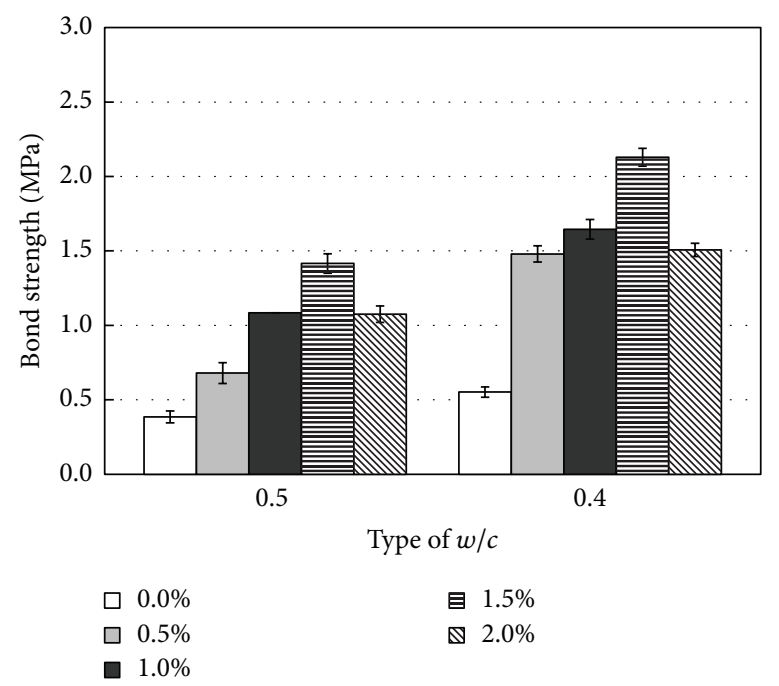

(a) Bond strength

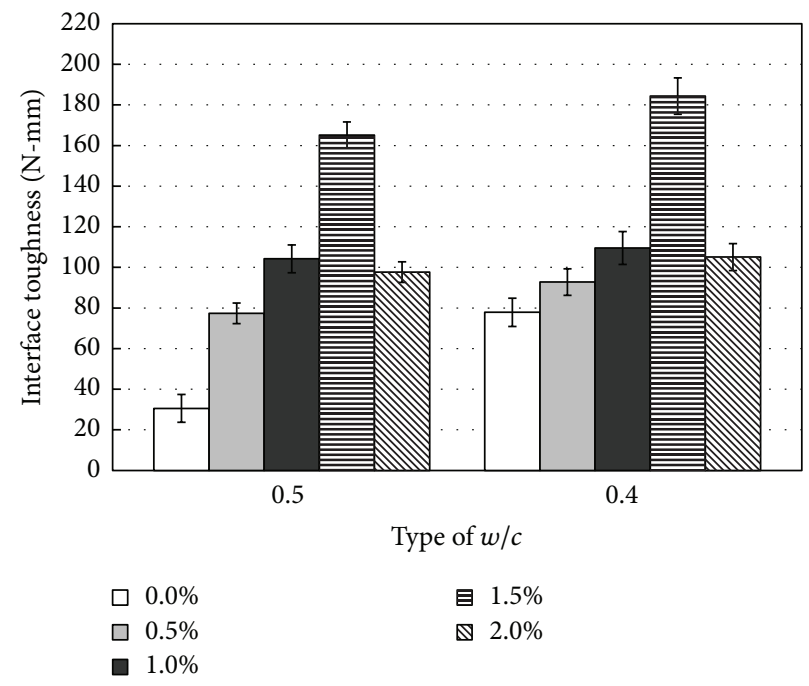

(b) Interface toughness

FIGURE 5: Bond strength and interface toughness of macrosynthetic fiber in LMHFRCCs.

strength. The pullout behavior before the onset of cracking and the behavior of the separation zone after crack generation were remarkable.

4.4. Bonding Strength and Interfacial Toughness. The bonding strength results are shown in Figure 5(a). As the carbon nanotube content increased from 0 to $0.5,1.0,1.5$, and $2.0 \%$, the bonding strength for the mix with $w / c=0.5$ changed from 0.39 to $0.68,1.08,1.42$, and $1.07 \mathrm{MPa}$, respectively, and that for the mix with $w / c=0.4$ changed from 0.55 to 1.48 , $1.64,2.13$, and $1.51 \mathrm{MPa}$. These results indicate that the nanotubes improved the bonding strength by suppressing crack propagation at the interface between the reinforcing fibers and the cement-based composites. The bonding strength increased up to a nanotube content of $1.5 \%$ but then decreased at $2.0 \%$. This trend is identical to that noted above for the compressive strength. In fiber-reinforced cement-based composites, the reinforcing fiber suppresses crack growth through continuous delivery of a tensile stress after crack generation and prevents brittle failure by distributing the tensile stress as the fiber is pulled out from the mortar. The interfacial toughness strongly influences the behavior after crack generation: the greater the interfacial toughness, the more ductile the cement-based composites become. Interfacial toughness is the mechanical energy consumed during the fiber pullout process. It corresponds to the area under the pullout stress-strain curve. The interfacial toughness results are shown in Figure 5(b). As the amount of carbon nanotubes increased from 0 to $0.5,1.0,1.5$, and $2.0 \%$, the interfacial toughness of the $w / c=0.5$ mix changed from 30.55 to 77.38 , $104.19,165.17$, and $97.66 \mathrm{~N}-\mathrm{mm}$, respectively, and that of the $w / c=0.4$ mix changed from 77.86 to $92.77,109.51,184.32$, and $105.08 \mathrm{~N}-\mathrm{mm}$, respectively. The interfacial toughness is affected by the behavior after crack generation and in the separation zone. The carbon nanotubes suppressed, through fiber bridging, the separation of the adhesive interface during pullout of the macrosynthetic fiber, thereby increasing

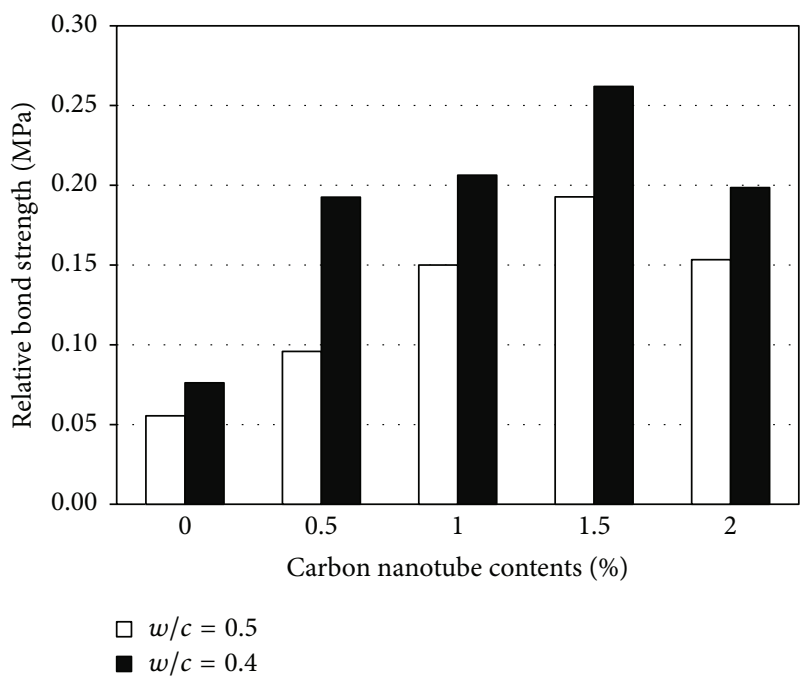

FIGURE 6: Relative bond strength of macrosynthetic fiber in LMHFRCCs.

interfacial toughness. A poorer dispersion of nanotubes at the $2.0 \%$ level detrimentally affected the quality of the adhesive interface, thus decreasing the interfacial toughness.

4.5. Relative Bonding Strength. To investigate bonding properties other than strength, the relative bond characteristic was calculated as follows [21]:

$$
\tau_{r}=\frac{\tau_{\max }}{\sqrt{f_{c k}}}
$$

where $\tau_{r}$ is the relative bonding strength, $\tau_{\max }$ is the bonding strength, and $f_{c k}$ is the compressive strength.

The relative bonding strength results are shown in Figure 6. For both $w / c=0.4$ and 0.5 , the relative bonding strength increased up to a carbon nanotube content of $1.5 \%$ 


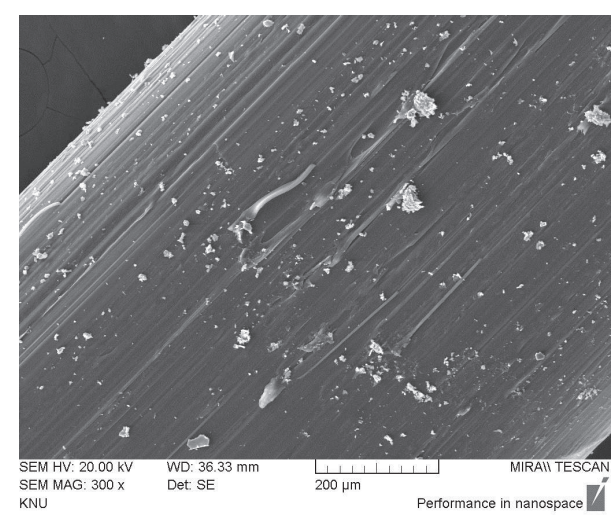

(a) $0 \%$

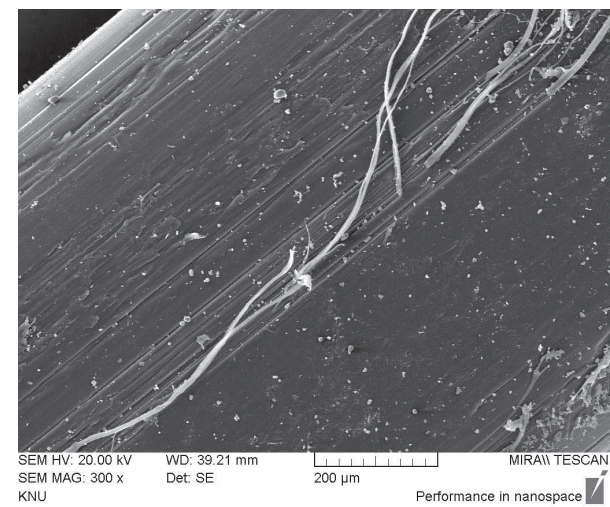

(c) $1.0 \%$

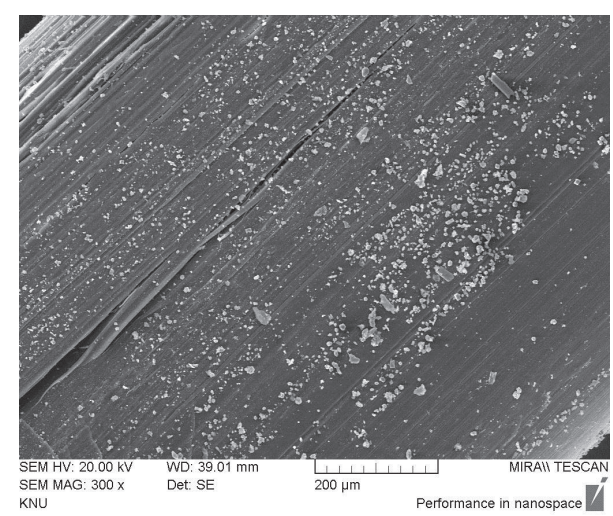

(b) $0.5 \%$

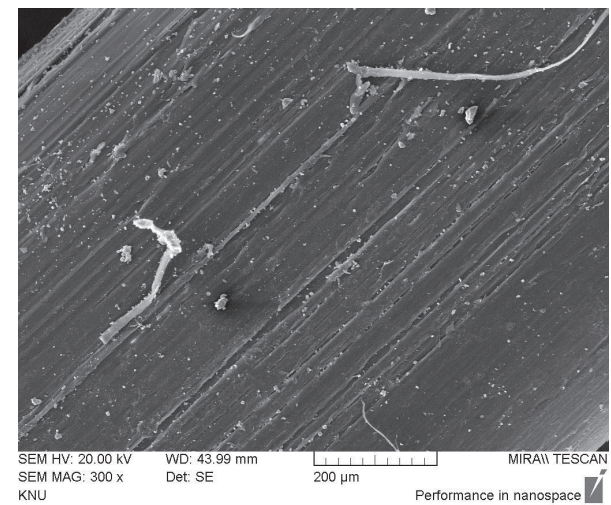

(d) $1.5 \%$

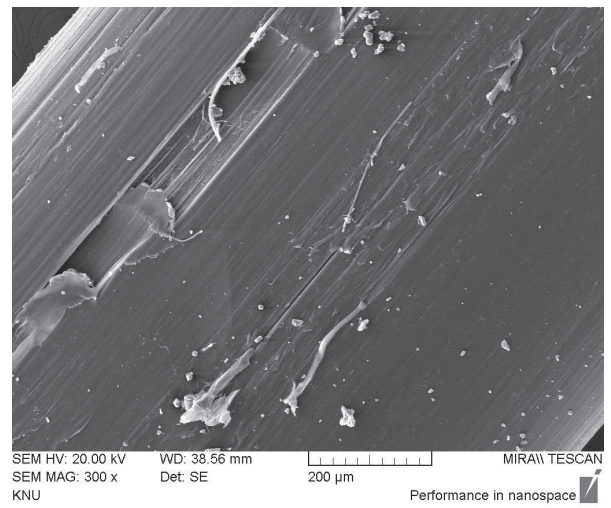

(e) $2.0 \%$

FIGURE 7: Microstructure of fiber surface in LMHFRCCs $(w / c=0.5)$.

and then decreased at $2.0 \%$. Up to the $1.5 \%$ level, the nanotubes increased the bonding strength by strengthening the interface between the macrosynthetic fiber and the cementbased composites. The lower relative bonding strength at a nanotube content of $2.0 \%$ was attributed to a nonuniform distribution of the nanotubes in the cement-based composites. These trends in relative bond strength were the same as those for bond strength. Therefore, regardless of the strength of LMHFRCCs, adding carbon nanotubes provided effective control over the bond strength of the macrosynthetic fiber and LMHFRCCs.
4.6. Microstructural Analysis. A variety of techniques have been used to investigate the bonding mechanisms of fiberreinforced cement composites. One technique is to analyze the fiber surface using scanning electron microscopy (SEM) following a bonding test $[10,13,14]$. Here, we performed SEM microstructural analysis of fibers drawn from samples with various carbon nanotube content.

The pulled-out fibers were examined using SEM (Figures 7 and 8). Scratching of the fiber surfaces was attributed to friction between the fiber and the cement-based composites 


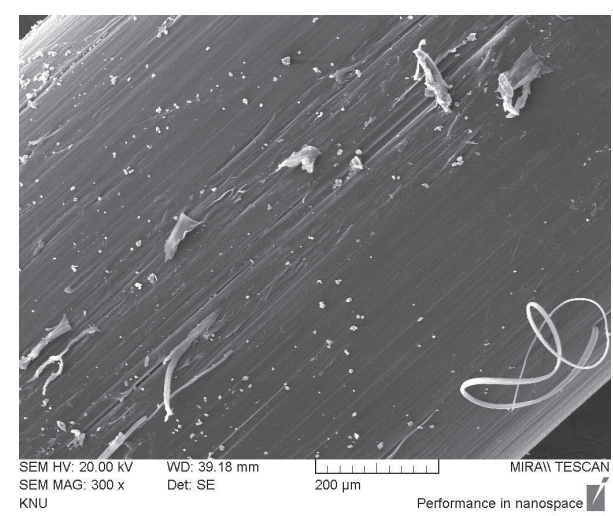

(a) $0 \%$

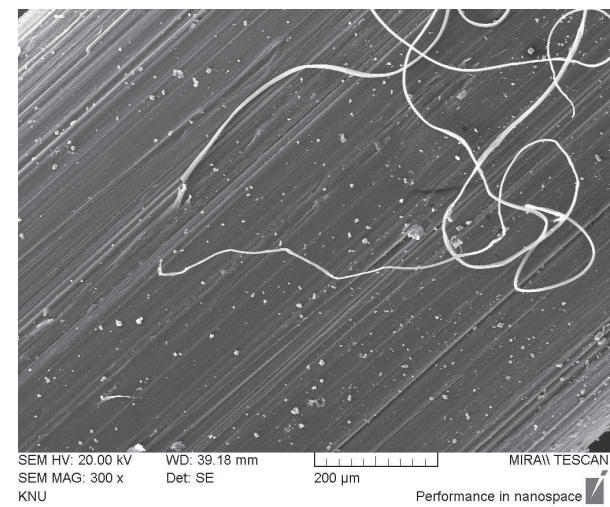

(c) $1.0 \%$

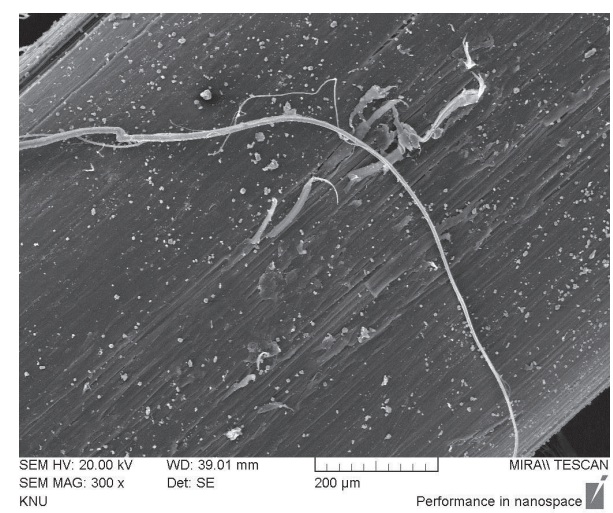

(b) $0.5 \%$

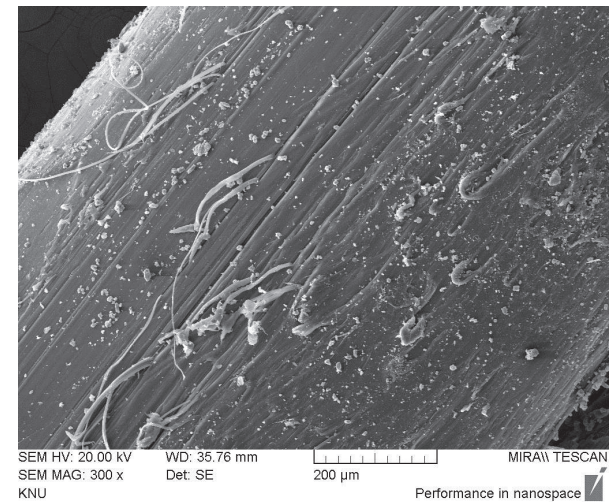

(d) $1.5 \%$

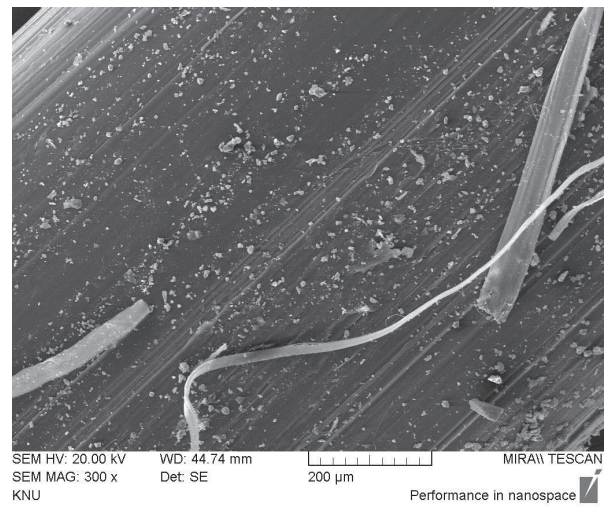

(e) $2.0 \%$

Figure 8: Microstructure of fiber surface in LMHFRCCs $(w / c=0.4)$.

as the fibers were withdrawn. The amount of surface scratching increased with the interfacial toughness up to a carbon nanotube content of $1.5 \%$; it was less severe at a content of $2.0 \%$. Figures 7 (a) and $8(a)$ show a small amount of scratching and tearing marks. Figures $7(\mathrm{~b})$ and $8(\mathrm{~b})$ show that scratching expanded over the entire surface of the fiber, and the number of tears increased. Figures $7(\mathrm{c})$ and $8(\mathrm{c})$ show that the area of the fiber surface subject to tearing increased, as did the amount of tearing. Figures $7(\mathrm{~d})$ and $8(\mathrm{~d})$ show still more scratching and tearing. Figures 7(e) and 8(e) show a slight reduction in tearing and scratching of the macrosynthetic fiber surface. The same results were obtained for both the $w / c=0.4$ and 0.5 mixes. More fiber tearing was also observed at the $1.5 \%$ level.

\section{Conclusions}

The effect of carbon nanotube content on the bonding behavior between macrosynthetic fiber and LMHFRCCs was evaluated using pullout tests for nanotube contents of $0,0.5$, 
$1.0,1.5$, and $2.0 \%$. The microstructure of the bonded surface of the pulled-out fibers was examined using SEM. The study findings may be summarized as follows:

(1) The slump value decreased with increasing carbon nanotube content and was almost zero at the $2.0 \%$ level. Therefore, the dispersion of carbon nanotubes decreased.

(2) Fiber pullout load-displacement curves revealed that the nanotube content affected the load required to generate the initial crack. In the separation (debonded) zone after the crack generation, strain hardening was observed; that is, the pullout load increased as the strain increased. The bonding strength increased as the carbon nanotube content increased from 0 to $1.5 \%$.

(3) The relative bonding strength indicated that the carbon nanotubes were also effective at strengthening the interface between the macrosynthetic fiber and the LMHFRCCs.

(4) SEM analysis revealed scratches on the surfaces of pulled-out macrosynthetic fibers. Such scratches were attributed to frictional forces during the pullout process. The trend in scratching severity followed the trend in interfacial toughness.

\section{Competing Interests}

The authors declare that they have no competing interests.

\section{Acknowledgments}

This research was supported by the Basic Science Research Program through the National Research Foundation of Korea (NRF) founded by Ministry of Education (NRF2013R1A1A4A01011776).

\section{References}

[1] G. Y. Li, P. M. Wang, and X. Zhao, "Mechanical behavior and microstructure of cement composites incorporating surfacetreated multi-walled carbon nanotubes," Carbon, vol. 43, no. 6 , pp. 1239-1245, 2005.

[2] A. Cwirzen, K. Habermehl-Cwirzen, and V. Penttala, "Surface decoration of carbon nanotubes and mechanical properties of cement/carbon nanotube composites," Advances in Cement Research, vol. 20, no. 2, pp. 65-73, 2008.

[3] G. Y. Li, P. M. Wang, and X. Zhao, "Pressure-sensitive properties and microstructure of carbon nanotube reinforced cement composites," Cement and Concrete Composites, vol. 29, no. 5, pp. 377-382, 2007.

[4] J. M. Makar and J. J. Beaudoin, "Carbon nanotubes and their applications in the construction industry," in Nanotechnology in Construction, Proceedings of the 1st International Symposium on Nanotechnology in Construction, P. J. M. Bartos, J. J. Hughes, P. Trtik, and W. Zhu, Eds., pp. 331-341, Royal Society of Chemistry, 2004.

[5] Z. S. Metaxa, M. S. Konsta-Gdoutos, and S. P. Shah, "Carbon nanotubes reinforced concrete. Nanotechnology of concrete: the next big thing is small," ACI Special Publications SP-267-2, 2009.

[6] M. S. Konsta-Gdoutos, Z. S. Metaxa, and S. P. Shah, "Multiscale mechanical and fracture characteristics and early-age strain capacity of high performance carbon nanotube/cement nanocomposites," Cement and Concrete Composites, vol. 32, no. 2, pp. 110-115, 2010.

[7] F. Pavia, A. Letertre, and W. A. Curtin, "Prediction of first matrix cracking in micro/nanohybrid brittle matrix composites," Composites Science and Technology, vol. 70, no. 6, pp. 916-921, 2010.

[8] Y. Sáez de Ibarra, J. J. Gaitero, E. Erkizia, and I. Campillo, "Atomic force microscopy and nanoindentation of cement pastes with nanotube dispersions," Physica Status Solidi A: Applications and Materials Science, vol. 203, no. 6, pp. 1076-1081, 2006.

[9] S. P. Shah, M. S. Konsta-Gdoutos, Z. S. Metaxa, and P. Mondal, "Nanoscale modification of cementitious materials," in Nanotechnology in Construction 3, Z. Bittnar, P. J. M. Bartos, J. Němeček, V. Šmilauer, and J. Zeman, Eds., pp. 125-130, Springer, Berlin, Germany, 2009.

[10] J.-Y. Jung, J.-S. Park, and C.-G. Park, "Bond properties of structural polypropylene fiber in hybrid nonstructural polypropylene and structural polypropylene fiber-reinforced latex-modified cement-based composites," Journal of Applied Polymer Science, vol. 127, no. 2, pp. 1221-1227, 2013.

[11] A. Bentur and S. Mindess, Fiber-Reinforced Cementitious Composites, Elsevier Applied Science, London, UK, 2009.

[12] Y.-W. Chan and S.-H. Chu, "Effect of silica fume on steel fiber bond characteristics in reactive powder concrete," Cement and Concrete Research, vol. 34, no. 7, pp. 1167-1172, 2004.

[13] S. Singh, A. Shukla, and R. Brown, "Pullout behavior of polypropylene fibers from cementitious matrix," Cement and Concrete Research, vol. 34, no. 10, pp. 1919-1925, 2004.

[14] C.-G. Park and J.-H. Lee, "Effect of styrene butadiene latex polymer contents on the bond properties of macro polypropylene fiber in polymer-modified cement-based composites," Journal of Applied Polymer Science, vol. 126, no. 2, pp. E330-E337, 2012.

[15] F. Collins, J. Lambert, and W. H. Duan, "The influences of admixtures on the dispersion, workability, and strength of carbon nanotube-OPC paste mixtures," Cement and Concrete Composites, vol. 34, no. 2, pp. 201-207, 2012.

[16] S. Roche, "Carbon nanotubes: exceptional mechanical and electronic properties," Annales de Chimie Science des Matériaux, vol. 25, no. 7, pp. 529-532, 2000.

[17] C. T. Sumathy, M. Dharakumar, M. Saroja Devi, and S. Saccubai, "Modification of cement mortars by polymer latex," Journal of Applied Polymer Science, vol. 63, no. 10, pp. 1251-1257, 1997.

[18] ASTM, "Standard test method for slump of hydraulic-cement concrete," ASTM C143/C143M-15, American Society for Testing and Materials, Philadelphia, Pa, USA, 2015.

[19] ASTM, "Standard test method for compressive strength of hydraulic cement mortars," ASTM C 109, American Society for Testing and Materials, Philadelphia, Pa, USA, 2005.

[20] Committee on Fiber Reinforced Concrete JCI-SF8, Method of Testing for Bonds of Fibers, Japan Concrete Institute, Tokyo, Japan, 1984.

[21] J. Xiao and H. Falkner, "Bond behaviour between recycled aggregate concrete and steel rebars," Construction and Building Materials, vol. 21, no. 2, pp. 395-401, 2007. 

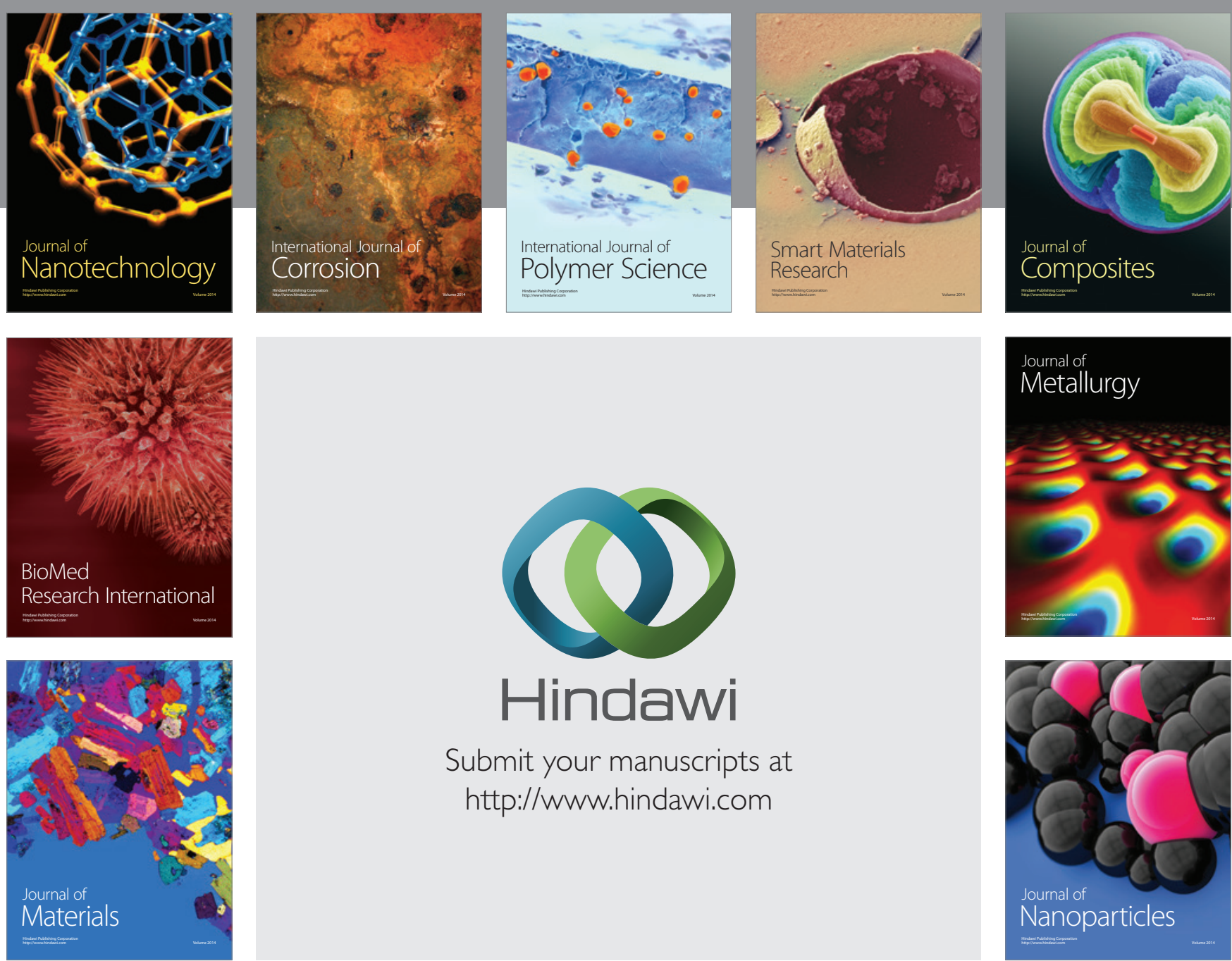

\section{Hindawi}

Submit your manuscripts at

http://www.hindawi.com

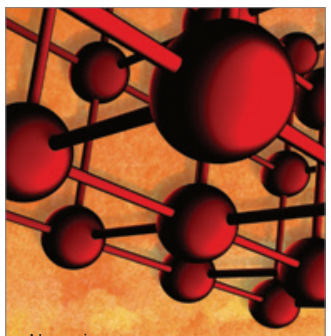

Materials Science and Engineering
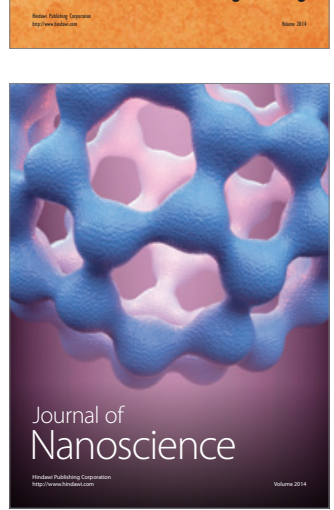
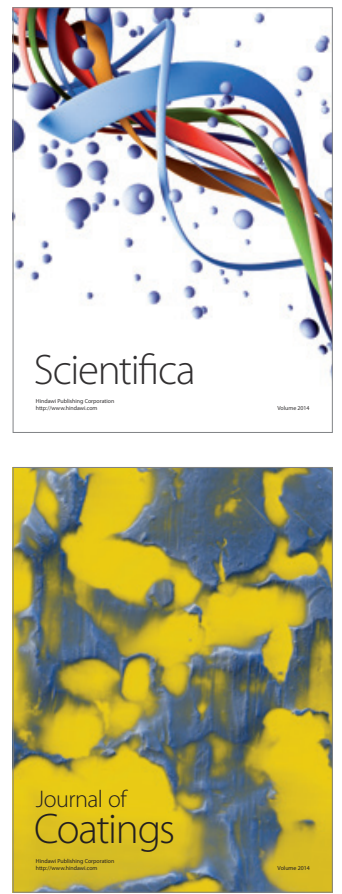
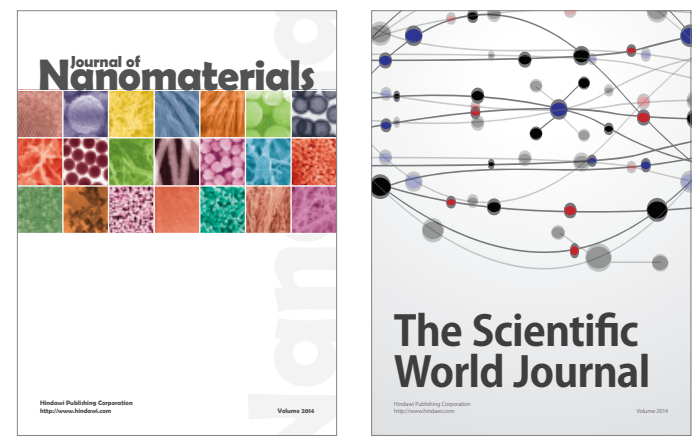

The Scientific World Journal
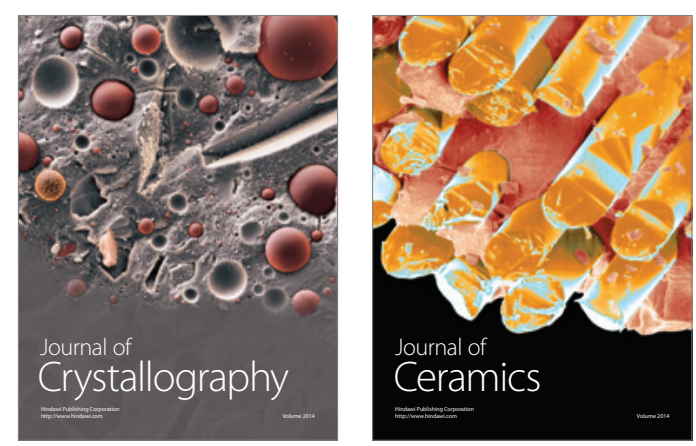
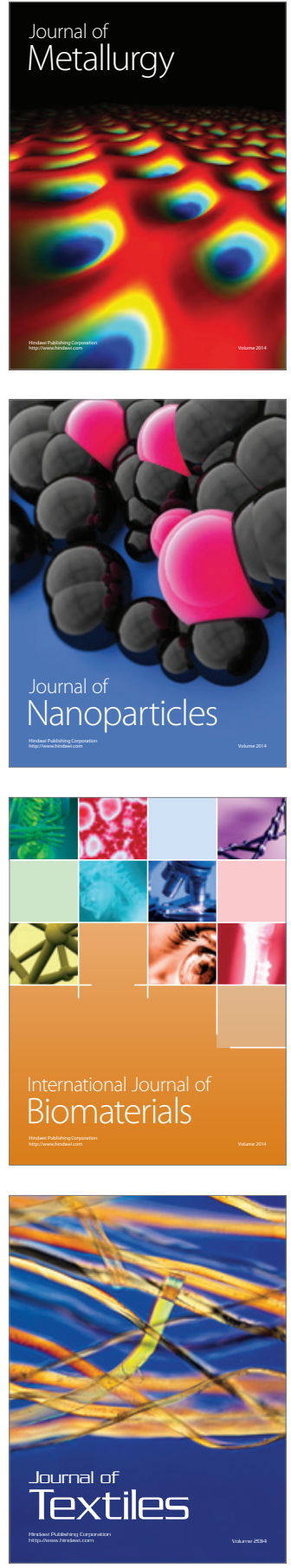